Bulgarian Academy of Sciences. Space Research and Technology Institute.

Aerospace Research in Bulgaria. 30, 2018, Sofia

DOI: https://doi.org/10.3897/arb.v30.e12

\title{
COMPOSITE METAL-CERAMIC AND METAL-POLYMERIC MATERIALS FOR FRICTION ASSEMBLIES OF NATIONAL CIVIL AIRCRAFTS
}

\author{
Andrii Bychkov ${ }^{1}$, Olha Nechyporenko ${ }^{2}$ \\ ${ }^{I}$ State Scientific and Research Expert-Forensic Center of the MIA of Ukraine. Kyiv \\ ${ }^{2}$ State enterprise "ANTONOV”. Ukraine, Kyiv
}

\begin{abstract}
Experience of using of metal-ceramic and metal-polymeric materials in friction assemblies of aeronautical engineering is generalized. Characteristics and conditions of operation of the sintered friction and antifriction materials are presented. Peculiarities of metal-fluoroplastic tapes of foreign production are considered. Efficiency of using of sintered and metal-polymeric materials in friction assemblies of modern civil aircrafts is shown.
\end{abstract}

One of the reasons of failure of components and units is wear, at that about $75 \%$ cases of failure are stipulated exactly by wear of the friction pairs. As far as the aircraft control systems, landing gear, hydraulic system, etc. are the systems working due to movement of their elements, importance of ensuring their reliable functioning becomes obvious [1].

Increased wear of the components in the friction assemblies in some cases violates air-tightness of the working space, in other cases normal conditions of lubrication, in third cases it causes loss of the mechanism precision, which worsens aircraft control and affects flight safety. Wear and damage of the surfaces reduce fatigue resistance of the components and may be reason of their failure even at insignificant stress concentrators and low nominal loads. Violation of normal interaction of components in the friction assemblies due to their wear may cause vibrations and impacts in the joints, and jamming and seizing of components - emergency situations. In this connection materials for work under friction conditions are referred to the most important in aircraft construction $[1,2]$.

In the context of triboengineering, the powder metallurgy is one of the most efficient methods of production of the materials (metal-ceramic and metal-polymeric materials) because it allows joining in one material different components specially selected for solution of a specific task. Materials of triboengineering designa- 
tion are able to meet whole complex of frequently contradictive requirements stipulated by specific conditions of the aviation engineering operation, which is practically impossible when using traditional materials $[3,4]$.

In structures of friction assemblies of national civil aircrafts the metal-ceramic iron-based (FMK-79) and copper-based (FMKM-1) friction materials are used. Use of sintered friction materials allows increasing longevity, reliability and efficiency of the friction assemblies, and creating new structures with high power intensity, wear resistance, heat resistance and high and stable values of the friction factor.

Sintered friction materials not just improve technical characteristics of aeronautical engineering, but also ensure its high economic efficiency due to increase of longevity of the friction assemblies and reduction of the operation expenses. In addition, in majority of cases safety of passengers and the crew depends upon reliable work of the aircraft friction assemblies [3, 4].

Items of friction designation represent a steel basis with sintered to it on one or two sides metal-ceramic linings from friction materials. Low-carbon (steel 20), medium-carbon (steel 45), chromium (12Cr13, 20Cr13) and low alloy steel (highgrade steel $30 \mathrm{CrMnSi}$ ) are used as the basis. For protection against corrosion and ensuring strong adhesion of the metal-ceramic linings to the steel basis, surface of the latter is galvanically nickel-plated.

For optimization of the friction material properties, different metal and nonmetal components are introduced into their composition, which, depending upon the created by them effect, may be divided into two groups:

- the components, which reduce predisposition of the friction couple to jamming;

- the components, which create and stabilize certain conditions [3].

For improvement of the antiscuffing properties and increasing wear resistance of the friction materials, the metals with low melting point (lead, tin) and non-metal substances (graphite, boron nitride, barite) are introduced into their composition. During friction without lubrication, when temperature of the friction surface exceeds melting point of the low-melting-point metal, lead and tin melt and form on the friction surface a lubrication film, which reduces friction factor. Due to this friction temperature reduces, molten metal again solidifies, which causes increase of the friction factor up to the initial level (principle of self-regulation). Formation of a liquid lubrication film enables smooth and stable slipping, which is especially important at increased temperatures, when metal matrix is more inclined to seizure [5].

Lubrication action of solid lubricant with laminated structure (graphite, boron nitride) is connected with presence of adhesion of the solid lubricant particles to the metal and difference in the bonding force between atoms and molecules in the elementary crystal layer and between separate layers [5]. 
Introduction of solid lubricants reduces wear of the metal-ceramic, enables more stable work of the friction pairs, however at that friction factor reduces. For the friction factor increase up to the required level, friction additives are introduced into composition of the materials - silicon oxide and molybdenum oxide, silicon carbide. Main task of the friction additives is ensuring of optimum level of the material adhesion to the working surface of the counter-body without its abrasive wear $[5,6]$.

Friction metal-ceramic FMKM-1 on basis of copper is used in friction electromagnetic and safety couplings of aviation units at dry friction and temperatures up to $200^{\circ} \mathrm{C}$. Friction factor of such material in pair with a chrome-plated steel at slip velocity up to $6.0 \mathrm{~m} / \mathrm{s}$ is $0.28 \div 0.30$ [6].

In comparison with the iron-based materials, the copper-based metal-ceramic scuffs significantly less mated component from steel or cast iron. Copper has high heat conductivity, which ensures good heat removal during friction [5].

After sintering the material FMKM-1 has hardness $300 \div 400 \mathrm{HB}$, after machining $-400 \div 600 \mathrm{HB}$. In sintered state at room temperature the metal-ceramic FMKM-1 has $\sigma_{\text {в }}=50 \div 60 \mathrm{MPa}, \sigma_{\text {в. bend }}=70 \div 80 \mathrm{MPa}, \sigma_{\text {в. compr }}=140 \div 150 \mathrm{MPa}$ $[1,6,7]$.

From the friction material FMKM-1 the brake shoes, friction disks for the onboard loading cranes of transport aircrafts, etc. are made (Fig. 1, $a$ ).

Friction disks with the metal-ceramic FMKM-1 are used in the limiting coupling of the mechanism located in the civil aircraft crew seats. Such mechanism ensures vertical movement of the set and its fixing in any place of the working movement range. At that, reliability of the mechanism with sintered friction disks is 45 flight hours, longevity is 30 years [8].

Friction metal-ceramic FMK-79 stands on the friction surface temperature up to $1000{ }^{\circ} \mathrm{C}$, and volumetric heating - up to $600{ }^{\circ} \mathrm{C}$, which is ensured due to the material basis - iron. Iron is pressed well, and relatively low cost makes use of iron economically advisable. For removal of the seizure and increase of heat conductivity up to $10 \%$ copper is introduced into composition of the material [8].

The friction factor of the metal-ceramic FMK-79 in pair with cast iron ChNMKh (ЧHMX) at slip velocity $20 \mathrm{~m} / \mathrm{s}$ is $0.3 \div 0.4[1,6,7]$.

At room temperature the FMK-79 metal-ceramic has hardness 800 $\div 1050 \mathrm{HRF}, \sigma_{\mathrm{B}}=40 \div 50 \mathrm{MPa}, \sigma_{\text {в. bend }}=110 \div 120 \mathrm{MPa}, \sigma_{\text {в. compr }}=250 \div 260 \mathrm{MPa}$. At temperature $600{ }^{\circ} \mathrm{C}$ mechanical characteristics of the material are on average $1.3 \div 1.5$ times lower $[1,6,7]$.

Brake disks with the metal-ceramic material FMK-79 are used in the combined wing extendable devices drive and in the brakes designed for braking of the flap and the slat control transmission in case of their mismatch. 
From the material FMK-79 the friction washers for the onboard loading cranes of transport aircrafts, load beams of the ground maintenance facilities, etc. are manufactured (Fig. 1, b) $[6,8]$.

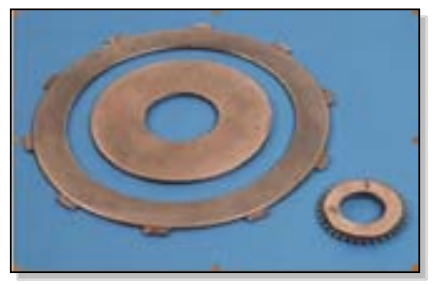

$a$

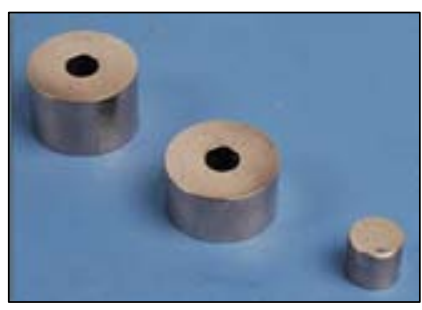

$c$

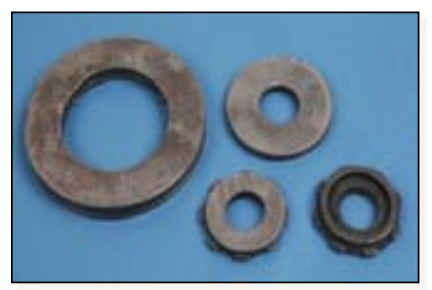

$b$

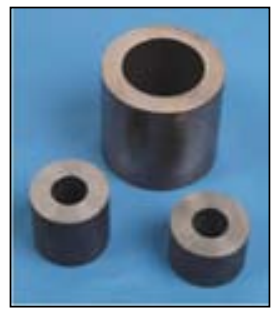

$d$

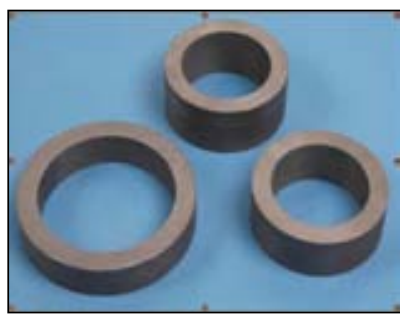

$e$

Fig. 1. Metal-ceramic billets of components with friction materials FMKM-1 (a), FMK-79 (b) and from antifriction materials $A M K-1(c), A M K-4(d), A M K-5(e)[6]$

Another class of tribotechnical materials for aeronautical engineering are powder (composite) antifriction materials.

Antifriction materials are the materials with low friction factor, which are used for work in units-carriers or in guiding units (sliding bearings). Such materials must be wear resistant, have good running-in ability, high tribotechnical properties, big carrying capacity, self-lubrication, volumetric and surface strength, high heat conductivity, corrosion resistance, sufficient endurance and fatigue resistance, good technological properties, low wear of conjugated with them surfaces, not seizure, stand the load, speed and temperature without failure and change of the shape and the quality. Such complex of properties is not peculiar for a separate metal or nonmetal. The task was solved due to creation of sintered composite materials, in which separate phases fulfil the assigned specific functions, ensuring, as a whole, a set of properties for the material necessary for specific conditions of work of the aviation unit friction assemblies $[2,4]$.

One of the main advantages of sintered antifriction materials is their selflubrication. It is ensured both due to the lubrication located in pores of the sintered 
materials, and due to the substances located directly in composition of the material, which play role of solid lubricant [6].

Use of the sintered antifriction materials as intermediate inserts is the most optimum structural decision for ensuring working ability of the friction assembly. In this case, structural materials, which practically do not participate in friction, ensure structural strength, and intermediate inserts, which are worn, may be easily replaced during the repair [1].

In friction assemblies of aeronautical engineering metal-ceramic materials on basis of copper (AMK-1, AMK-4) and nickel (AMK-5) and metal-polymeric materials (BFG-50M, metal-fluoroplastic tape) are used.

Antifriction sintered material $A M K-1$ represents a tin bronze with additives of graphite. In process friction graphite gradually forms a film on surface of the counter-body, which constantly restores in separate sections of the friction surface in case of a mechanical damage. Bronzografite works more reliably than materials without graphite and replace cast bronze and brass in friction assemblies.

The AMK-1 material has hardness after sintering $250 \div 350 \mathrm{HB}$, and after machining or calibration $-300 \div 450 H B[1,6]$.

From the bronzografite AMK-1 different friction components are manufactured which work under conditions of self-lubrication at slip velocity up to $1 \mathrm{~m} / \mathrm{s}$ and load $4 \div 5 \mathrm{MPa}$. At that, effect of self-lubrication is ensured both due to presence of graphite in composition of the material and due to lubricant present in the pores after its impregnation [6].

It should be noted that impregnated metal-ceramic bearings have a number of advantages in comparison with the cast ones, in particular:

- high running-in ability and smoothness of movement;

- possibility of use in the cases, when lubrication process using conventional methods is impeded or impossible and when it is impossible to remove products of attrition of the friction pair;

- possibility of using during cyclic movement and rotation with low speeds, when cast bearings have not integrated lubrication film;

- possibility of installation in vertical and inclined positions (in such positions oil just escapes from the cast bearings);

- reduction of oil consumption;

- reduction of the friction pair wear $[3,6,8]$.

Bushings from the sintered antifriction material AMK-1 working under self-lubrication conditions are used in landing searchlights of the aircraft, simulators of different aviation units, etc. (Fig. 1,c).

For friction assemblies of aeronautical engineering working at increased loads and temperatures use of liquid lubrication substances is not advisable, because 
they either are squeezed out or burn out. In these cases sintered bronzes are used, properties of which are significantly improved by introduction of alloying metals and substances playing role of solid lubricants $[6,8]$.

Bushings from the sintered complexly alloyed bronze $A M K-4$ are installed in "dry" friction zones with working temperature up to $350^{\circ} \mathrm{C}$ (Fig. $1, d$ ). The material contains up to $10 \%$ solid lubricant of layered structure, which enables reduction of the friction factor, wear and probability of the conjugated components seizure. Within temperature range $300 \div 350{ }^{\circ} \mathrm{C}$ at load up to $5 \mathrm{MPa}$ and slip velocity $0.5 \mathrm{~m} / \mathrm{s}$ in pair with counter-body from steel 9Cr18 (9X18 in Russ.) without lubrication the metal-ceramic friction factor is $0.20 \div 0.24$ [6].

At room temperature the metal-ceramic AMK-4 has hardness $550 \div 750 \mathrm{HB}$, $\sigma_{\text {в. bend }}=130-140 \mathrm{MPa}, \sigma_{\text {в. compr }}=250-280 \mathrm{MPa}$; at temperature $350{ }^{\circ} \mathrm{C}-$ hardness is $400 \div 650 \mathrm{HB}, \sigma_{\text {B. bend }}=70 \div 90 \mathrm{MPa}, \sigma_{\text {B. compr }}=160 \div 180 \mathrm{MPa}[1,6,7]$.

Sintered nickel-based antifriction materials are used for manufacturing of friction assemblies working under especially hard conditions. In pure form, nickel is characterized by high plasticity and very low antifriction properties during work without lubrication. That is why for manufacturing friction assembly components multicomponent nickel-based alloys containing strengthening and antiscoring additives are used. Part of the nickel in such alloys is replaced by iron and copper. Alloys with high content of nickel have good corrosion resistance $[4,6]$.

During flights in clouds, in majority of cases ice formation occurs, which is connected with presence in the atmosphere of water in dispersed liquid state at negative temperatures. At that, flight characteristics of an aircraft significantly worsen (vertical rate of climb reduces, ceiling and maximum flight speed reduce, increases fuel consumption and required power for flight at the assigned speed), and jamming of the aircraft control systems is possible. For protection of aircraft against ice formation, the anti-icing systems have been developed, the action of which is based on heating of the surface, which it is necessary to protect, by hot air. For compensation of the pipeline length change, special compensators are used at significant temperature differentials, which admit linear and angular movements $[6,8]$.

Nickel-based bushings from the antifriction metal-ceramic AMK-5 enter into composition of the compensators made from titanium alloys or corrosion resistant steels (Fig. 1,e). At temperature $550{ }^{\circ} \mathrm{C}$, slip velocity reduces up to $0.2 \mathrm{~m} / \mathrm{s}$ and at the load $1.5 \mathrm{MPa}$ in pair with the counter-body from steel $9 \mathrm{Cr} 18$ (without lubrication) the friction factor of the antifriction metal-ceramic AMK-5 equals $0.20 \div 0.24$. At temperature $450{ }^{\circ} \mathrm{C}$ the metal-ceramic AMK-5 has $\sigma_{\text {B. bend }}=120 \div 170 \mathrm{MPa}, \sigma_{\text {в. compr }}=200 \div 270 \mathrm{MPa}[6]$.

Bushings from the metal-ceramic AMK-5 are used in the non-return valve design, which ensures protection of the aircraft airline system against return airflow (air temperature at the inlet is $500{ }^{\circ} \mathrm{C}$ ). 
In mobile connections of aeronautical engineering seamless and wrapped metal-fluoroplastic bushings with flange (Fig. 2) and without flange may be used. Depending upon standard size, number of such bushings in the aircraft may achieve hundreds and sometime thousands pieces.

Operating life of metal-fluoroplastic bushings working without lubrication at reciprocating-rotary motion with average slip velocity up to $0.04 \mathrm{~m} / \mathrm{s}$, load $100 \mathrm{MPa}$ and deviation angle $\pm 30^{\circ}$ is not less than $10^{5}$ cycles; friction factor after $10^{5}$ cycles does not exceed 0.12 . Metal-fluoroplastic bushings stand static load not less than $300 \mathrm{MPa}$; at that, residual deformation does not exceed $0.02 \mathrm{~mm}$ (or $0.25 \mathrm{~mm}$, if internal diameter of the bushing is more than $12 \mathrm{~mm}$ ). Metal-fluoroplastic bushings preserve their working capacity in the process after cyclic change of the temperature from -60 to $+250{ }^{\circ} \mathrm{C}$ as well [6].

Mentioned complex of properties is stipulated by structure of the metalfluoroplastic tape, which is used for making bushings. Metal-fluoroplastic tape (MFT) represents a three-layer composition consisting from the base (a bimetal copper-plated tape from carbon steel), a porous layer (spherical particles of tin bronze sintered on one side of the copper-plated base) and antifriction layer (fluoroplastic filled by molybdenum disulfide, which covers by a thin film spherical particles of the bronze and fills voids of the porous layer) (Fig. 3) [9].

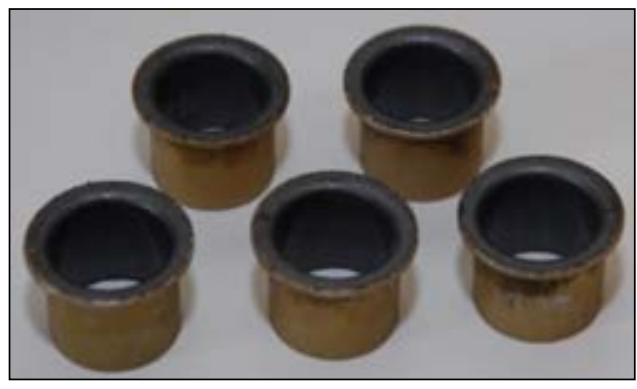

Fig. 2. Metal-fluoroplastic bushings with flange

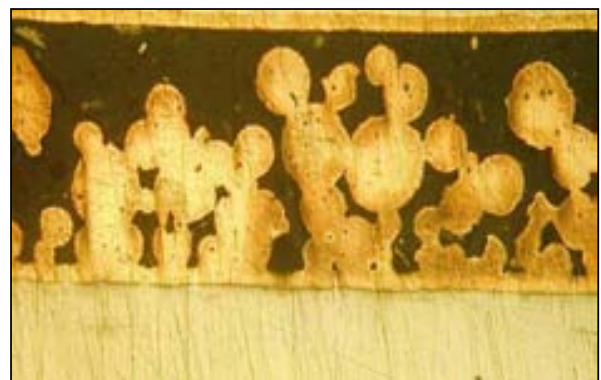

Fig. 3. Metal-fluoroplastic tape structure (Russia) [1]

Such material integrates high strength of the basis with good antifriction properties of the filled fluoroplastic, which is strongly held on the working surface by the porous bronze layer, which, in its turn, also imparts to the material certain antifriction properties [10].

During fabrication of MFP, a layer of spherical tin bronze particles is sintered to the steel copper-plated basis, then the tape is calibrated and fill pores with fluoroplastic with molybdenum disulfide. Then the paste from the filled fluoroplastic is dried at temperature $80 \div 90{ }^{\circ} \mathrm{C}$ and sintered at temperature $380 \div 390{ }^{\circ} \mathrm{C}$ 
with simultaneous calibration by the rolls heated to the same temperature. The final operation is additional calibration of MFP after its cooling [4].

Before starting the production, MFP pass obligatory metallographic control and control of strength and quality of sintering, stamping capacity according to Erickson method [6].

It should be noted that although composition of MFP of different producers is, as a whole, similar, in relation to the structure, dimensional parameters of the MFP constituents and chemical composition of the basis material (steel brand) significant differences exist (Fig. 4).

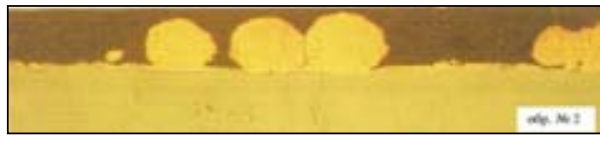

$a$

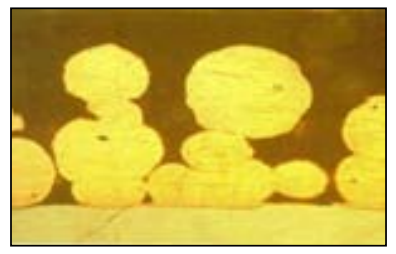

$c$

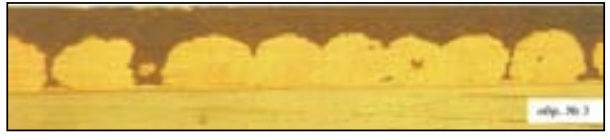

$b$

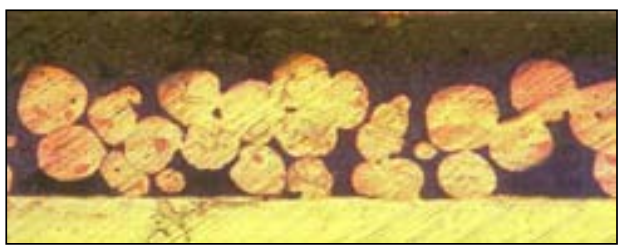

$d$

Fig. 4. Metal-fluoroplastic tape structure:

a) MFP of DU grade (Slovakia);

c) MFP of $M U$ grade (Italy); b) MFP of DP4 grade (Slovakia);

d) MFP of SF-1 grade (China) [11]

So, for example, MFP samples of the DU and the DP4 grades (Fig. 4, $a, b$ ) of Slovakian production have big general thickness, a thinner bronze layer and smaller average dimensional deviations from those established in the normativetechnical documentation used in the national aircraft construction. At that, porous layer is characterized by non-uniform single-row distribution of the bronze spherical particles: both their fusion with each other and placement at significant distance from each other is observed. Nevertheless, control of working capacity of the wrapped bushings from MFP of the DP4 grade within the volume of periodic tests showed their correspondence to the standard requirements adopted in national aircraft construction: friction factor after $10^{5}$ test cycles equaled 0.065 , wear $-0.001 \div 0.02 \mathrm{~mm}$ per a side $[11,12]$.

Metal-fluoroplastic tape of the SF-1 grade (Fig. 4, $d$ ) of Chinese production is characterized by satisfactory sintering of the bronze layer, qualitative sintering of the bronze granules and corresponds to the quality criteria established during tests according to Erickson method. Bushings from the mentioned tape passed without 
remarks longevity (friction factor after $10^{5}$ tests -0.039 , wear $-0.01 \div 0.05$ per a side) and deformation tests, as well as the resistance tests at cyclic change of the temperature according to the standard, which regulates methodology of the type tests $[11,12]$.

Type tests of bushings from MFP of the SF-1 grade in composition of universal joints working without renewal of the lubrication also confirmed their correspondence to requirements of the standard on wear resistance (wear after $2 \cdot 10^{6}$ test cycles was not more than $0.16 \mathrm{~mm}$, the norm being not more than $0.20 \mathrm{~mm}$ ) and moisture resistance [11].

Positive results of the complex of investigations allowed using MFP of the SF-1 grade in production of assemblies and units of aeronautical engineering.

Despite high operation properties of metal-fluoroplastic bushings, a serious problem of their corrosion damage exists. One of the options of solution of this problem is replacement in the MFP of the basis from carbon steel for the corrosionresistant steel [11].

From MFP of the SF-1SS grade (China) on basis from the corrosion-resistant steel the inserts into the hinge bearings working without lubrication are made.

Self-lubrication material BFG-50M represents a three-layer composition consisting from the base (tin bronze), a sintered porous bronze layer from nonspherical particles of tin bronze and antifriction layer from fluoroplastic filled with graphite. Such material is designed for work at slip velocity up to $1 \mathrm{~m} / \mathrm{s}$ and load $100 \mathrm{MPa}$ within wide range of temperatures (from -60 to $+250{ }^{\circ} \mathrm{C}$ ) and vibrations. The material friction factor is $0.06 \div 0.09[6,7]$.

This material was developed for fabrication of components with friction surface of complex configuration - nuts (Fig. 5). Use of such nuts allowed reducing weight and overall dimensions of the slipping friction assemblies in structures of propeller mechanisms of the aircraft and excluding time of scheduled maintenance and preflight preparation $[6,7]$.

In addition to the details with a screw friction surface, the material BFG$50 \mathrm{M}$ is also used in other aircraft friction assemblies. So, inserts into the control column, rollers of the cargo door shutters of transport aircraft, sliding bearings for the wing extendable devices control, thrust washers for limiting couplings, etc. are made from it [6].

Efficiency of using sintered bushings from the BFG-50M material instead of similar bushings from metal-fluoroplastic is confirmed by positive results of the complex of tests according to the standard requirements, which establish volume and methodology of the tests for metal-fluoroplastic bushings (friction factor after $10^{5}$ cycles of tests is 0.079 , wear is $0.01 \div 0.05$ per a side) $[6,9]$.

Advantages of the powder metallurgy technology during fabrication of bushings from the material BFG-50M in comparison with the traditional technology 
of bushing fabrication from MFP by the method of deep drawing are relative simplicity of the technology and the fixtures and equipment; absence of a set of transitions like during drawing of the bushings; possibility of simultaneous sintering of a big number of the bushing ingots of one or several unit sizes depending upon the furnace load; possibility of removal of the sintered porous layer in case of presence of defects in it and its repeated sintering [9].

The powder metallurgy technology allows manufacturing sintered bushings from the self-lubricating material BFG-50M both with flange and without a flange (Fig. 6).

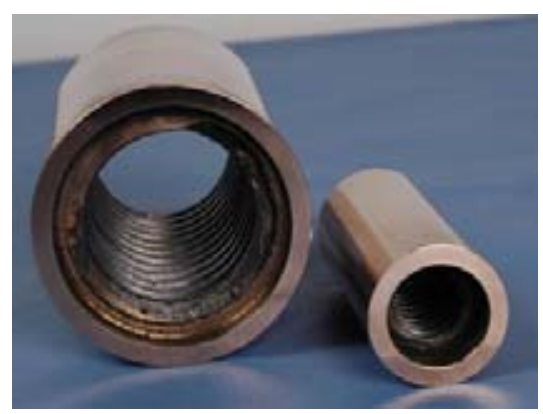

Fig. 5. Billets of nuts from the material BFG-50M

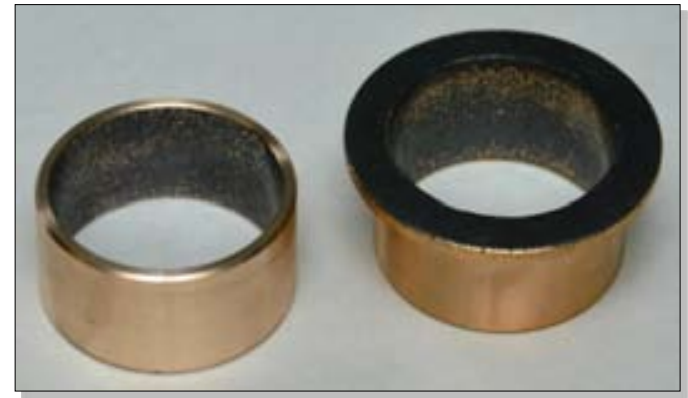

Fig. 6. Bushing without a flange (to the left) and with a flange (to the right) from the material BFG-50M [9]

Use of fluoroplastic-based antifriction coatings allows simplifying design of the compensators used for compensation of thermal, mounting and other movements during mounting of "hot" pipelines of the aircraft air system (Fig. 7). Absence of a crossbar in such compensators due to its replacement for a spherical element with antifriction fluoroplastic coating (Fig. 8) allowed reducing total hydraulic resistance in mounting of the aircraft air preparation system and reducing the compensator mass, which is especially important in aircraft construction. Power schemes of the pipelines with use of the hinge compensators with fluoroplasticbased antifriction coatings reduce loads on the system fixing elements and therefore, the aircraft framework [13]. 

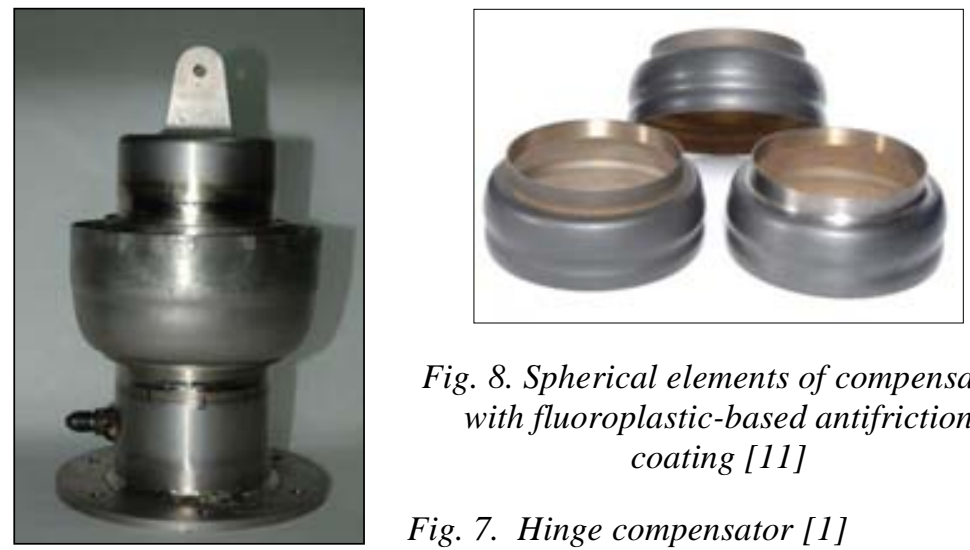

Fig. 8. Spherical elements of compensator with fluoroplastic-based antifriction coating [11]

Fig. 7. Hinge compensator [1]

So, experience of operation of the metal-ceramic and metal-polymeric materials proves efficiency of these materials for ensuring reliability, quality and service life of the aeronautical engineering friction assemblies. The powder metallurgy technology has huge potential in the field of creation of the materials with unique properties, the use of which will allow solving principally new tasks connected with ensuring of flight safety.

\section{Reference}

1. Molyar, A. G., A .A. Kotsyuba, and A.S. Bychkov, O.Yu. Structural materials in aircraft construction / Nechyporenko - Kiev: KVITS, 2015. 400 p.

2. Garkunov, D. N. Tribotechnics: Textbook for High Schools / D.N. Garkunov. - Moskow: Mashinostroenie, 1989. 328 p.

3. Powder metallurgy. Sintered composite materials: Trans. for German (Edited by V. Shatt), Moskow: Metallurgy, 1983. $520 \mathrm{p}$.

4. Mitin, B. S., Vasiliev V. A. Powder metallurgy of amorphous and microcrystalline materials. Moskow: Metallurg, 1992. 128 p.

5. Fedorchenko, I. M., V. M. Kryachek, and I. I. Panaioti. Modern friction materials. Kiev: Naukova Dumka, 1975. $336 \mathrm{p}$.

6. Kotsyuba, A. A., A. S. Bychkov, O. Yu. Nechyporenko, and I.G. Lavrenko. Powder materials for aviation and rocket-space technology. Kiev: KVITS, 2016. 304 p.

7. Semenchenko, V. P., S. G. Kushnarenko, S. A. Bychkov, and O. Yu. Nechyporenko. Technological processes of receiving details of planes by method of powder metallurgy: Textbook. Kharkiv: KhAI, 1992. 64 p.

8. Molyar, A. G., O. Yu. Nechyporenko, V. P. Semenchenko, and I. M. Romashko. Metalceramic of triboengineering designation in aircraft structures "AN". Technol. systems. 2006, 4, 18-22. 
9. Bychkov, A. S., I. G. Lavrenko, O. Yu. Nechyporenko et al. Assessment of operation characteristics of bushings from the material BFG-50M instead of metal-fluoroplastic in aircraft friction assemblies. Bulletin of machine building and transport. 2016, 1, 4-11.

10. Fedorchenko, I. M., Pugina L. I. Composite sintered antifriction materials. Kiev: Naukova dumka, 1980. 404 p.

11. Bychkov, S. A., I. G. Lavrenko, O. Yu. Nechyporenko et al. Present status and prospects of using MFP of new producers in aircraft friction assemblies. Technolog. systems. 2014, 4, 9-21.

12. Bychkov, S. A., I. G. Lavrenko, and O. Yu. Nechyporenko et al. Investigation of the metal-fluoroplastic characteristics of different producers for elements of aviation structures. Open information and computer integrated technologies. Kharkiv: KhAI. 2013, 59, 343-53.

13. Kostornov, A. G., A. G. Molyar, A. V. Nenakhov, and O. Yu. Nechyporenko. Polytetrafluorethylene-based antifriction materials for swing joints of pipelines. Phys.-chem. mechanics of materials. 2005, 1, 111-13.

\title{
МЕТАЛОКЕРАМИЧНИ И МЕТАЛОПОЛИМЕРНИ МАТЕРИАЛИ ВЬВ ФРИКЦИОННИ ВЪЗЛИ НА САМОЛЕТИТЕ ОТ ГРАЖДАНСКАТА АВИАЦИЯ
}

\author{
А. Бичков, О. Нечипоренко
}

\section{Резюме}

Обобщен е опита в използването на металокерамични и металополимерни материали във фрикционни възли в аеронавтиката. Представени са характеристиките и условията на работа на синтеровани триещи и антифрикционни материали. Разглеждат се особеностите на металофлуоропластичните ленти, чуждестранно производство. Показана е ефективността на използването на синтеровани и металополимерни материали в триещите се детайли на съвременните граждански самолети. 